\title{
Recognition of the Problematic Situations in Industrial Systems with Intellectual Support
}

\author{
V. Volochienko \\ Bauman Moscow State Technical University (BMSTU), \\ Moscow, Russia \\ Corresponding author: voko2010@rambler.ru \\ S. Falko \\ Bauman Moscow State Technical University (BMSTU), \\ Moscow, Russia \\ E-mail: falko@controlling.ru \\ E. Postnikova \\ Economics and Production Organization Department, \\ Bauman Moscow State Technical University (BMSTU), \\ Moscow, Russia \\ E-mail: postnikova.el@yandex.ru
}

(Received December 23, 2018; Accepted June 6, 2019)

\begin{abstract}
The factors responsible for the emergence of problematic situations in the company's production, economic, financial and economic activities are the unacceptable controlled disturbances of the external and internal environment of the enterprise and the unacceptable deviations of the actual states of the execution or management processes from the required ones, impeding (creating threats) or contributing (creating potential opportunities) achievement of the established objectives of the functioning and development of the enterprise. The essence of recognition of problem situations is considered and analyzed. A specialized system for recognizing problematic production situations is presented as a complex dynamic automated (automatic) system that realizes in real time the transformation of input information about a problem situation that has arisen in the course of production and economic activity into output information about its belonging to a certain reference class of problem production situations. Examples are given of the use of specialized systems for recognizing problematic production situations in the operational management of production, innovation processes and processes of functional maintenance of production and innovation processes implemented at the enterprise. Named the main tasks solved in the design, creation and operation of specialized systems for recognizing problematic production situations, and the methods used in the course of solving them. The advantages of using specialized systems for recognizing problem situations in the production and economic activities of production systems with intellectual support are indicated.
\end{abstract}

Keywords- Production, Intellectual support, Digital economy, Problem situation, Recognition, Specialized recognition system, Artificial neural network.

\section{Introduction}

Specialists in the field of artificial intelligence, organization, production automation and management, a number of industrial companies consider the development of production systems to be promising based on the widespread introduction of intellectual support in their internal environment (elements, components, processes, subsystems and production systems in general), the creation of "intellectual, smart productions" (Verhagen, 1985; Heikin, 2006; Badalova and Volochienko, 2014) They should integrate tools and items of production with intellectual support, 
International Journal of Mathematical, Engineering and Management Sciences

Vol. 4, No. 6, 1434-1447, 2019

https://dx.doi.org/10.33889/IJMEMS.2019.4.6-113

intellectualized workstations for employees, network communication tools, the internet, as well as highly productive means of collecting, transmitting and processing large amounts of information in real time. Such production systems are planned to be created within the framework of the fourth industrial revolution, the so-called "Industry 4.0", and also during the implementation of the Digital Economy Development Program in the Russian Federation until 2035.

The digital (electronic) economy, based on the use of electronic technologies, electronic infrastructure and services, technologies for analyzing large volumes of data and forecasting in order to optimize production, distribution, exchange and consumption, will allow for the production systems: real-time data acquisition; management of economic, production processes based on extensive use of the results of automated analysis of large amounts of data; real-time response to changes and interactivity of the environment; high speed of decision-making; orientation to a specific user (Blagoveshchenskaya et al., 2016; Chernykh et al., 2016; Kostin et al., 2017; Grishunin and Suloeva, 2017; Zegzhda et al., 2017).

The forthcoming robotization of the industry, creation of production systems with intellectual support, end-to-end automation and integration of production and management processes into a Single Information System ("from equipment to the Ministry"), high speed of decision-making in real time and many other opportunities realized by industry 4.0, digital economy in the field of production, are closely connected with the need for wide application of methods and systems of object recognition, processes, situations of internal and external environment of enterprises to achieve the goals of their operation and development (Drobintsev et al., 2014; Klochkov et al., 2017a). We consider the essence, purpose, methods of application of methods and specialized systems of recognition of problem situations arising in the process of targeted production and economic activity of production systems.

\section{The Theoretical Bases of Ascertaining and Recognition of Problematic Situations}

In the implementation of targeted industrial and economic activities implemented at the enterprise innovation processes (preparation of production, research and innovation), production processes (main, auxiliary, service), the functional processes of service production and innovation processes (logistics, marketing, financial support, training, performing management functions, etc.) as a result of perturbations external and internal environment occur current challenges and problematic situations (Gazizulina et al., 2017; Klochkov et al., 2017b; Rudskoy et al., 2019). These disturbances that affect the ongoing execution and management processes, the material, labor, energy, financial, information and other resources involved in them can be observable and unobservable. Observable disturbances, fixed in the execution and control processes at the time of their occurrence, are called controlled. And unobservable disturbances, which are not fixed in the execution and control processes at the time of their occurrence, are called uncontrollable. The results of the action of uncontrolled disturbances are manifested in the form of deviations of the actual (actual) states of the execution and (or) control processes from the target (desired) ones. Controlled disturbances and deviations of the actual states of the execution or control processes from the target states can be permissible and unacceptable (Volochienko and Falco, 2016).

The admissible controlled disturbances and deviations of the actual states of the execution or management processes from the target states give rise to current tasks, the solution of which is not problematic for executors or managers and is implemented through the implementation of traditional organizational measures ("weak regulatory influences") aimed at the involved and reserve resources. And inadmissible controlled disturbances and deviations of the actual states of 
International Journal of Mathematical, Engineering and Management Sciences

Vol. 4, No. 6, 1434-1447, 2019

https://dx.doi.org/10.33889/IJMEMS.2019.4.6-113

the execution or control processes from those required in the production, economic and financialeconomic activities of the enterprise create the need to resolve the problems arising in specific circumstances-problem situations (Bosikova et al., 2017; Silkina, 2017; Gromova, 2019). That is, they create the need for purposeful identification of possible options for resolving a problem situation and choosing from them a certain option - a solution. The problem can be the detection at a certain point in time of a significant inconsistency of the actual state of the production system with its target (required, planned) state, for example, established by a strategic or tactical or operational plan for manufacturing products, performing work, rendering services, or developing aspects of the production and economic activities of the enterprise, arising as a result of the action of disturbances that were not fixed at the time of their appearance and not detected during their time actions in the production system, i.e. uncontrollable disturbances. Or in the appearance of perturbations fixed at the time of their appearance or detected at a certain time during their time in the production system, i.e. controlled disturbances that create threats or potential opportunities. These disturbances have not yet led to a significant disagreement between the actual state of the production system and its target state, but can lead to it in the not yet-coming periods of time. The problem can also arise in the emergence of the need to change the strategic or tactical or operational objectives of the operation of the production system. These problem situations need to be fixed in real time (RT), that is, to state the fact of their detection at the time of their occurrence, and to make decisions on their resolution with a speed commensurate with the speed of the execution or control processes (Izmaylov et al., 2015). Fixation (ascertaining the facts of occurrence), an analysis of these problem situations and decision-making on their resolution in the RT can be carried out on the basis of the development and use of specialized recognition systems.

The recognition is a method of establishing the belonging of an unknown element of the environment (object, process, situation, etc.) to a specific reference class of similar elements. If the recognition method is for recognizing printed characters, then it cannot be used to recognize problem situations. The recognition process is realized by comparing a posteriori data (characteristic values) about the unknown unknown element of the environment (an object, phenomenon, situation, etc.) with a priori information about the aggregate of similar elements of the medium based on the recognition algorithm. To realize the problematic production situations arising in the production and economic activities of an enterprise, taking into account the designation, the purposes of recognition, the places of their occurrence in the processes implemented at the enterprise, specialized recognition systems should be created. A specialized system for recognizing problematic production situations in the general case can be considered as a complex dynamic automated (automatic) system that realizes in real time the collection, transmission of input information about each problem situation that arose in the course of production and economic activities, its processing and presentation of the result of recognition in the form of output information about the belonging of the investigated problem situation to a certain reference class of problem production situations (Chernykh et al., 2016). Based on the obtained recognition results in subsystems of execution and (or) management of the enterprise, measures are taken to resolve the emerging problematic production situation.

\section{Data and Methods for Developing Specialized Systems for Recognizing Problematic Industrial Situations}

The purpose of using specialized systems for recognizing problematic production situations (SSRPPS) differs in the production, innovation processes and processes of functional maintenance of production and innovation processes implemented at the enterprise. For example, the management of the implementation of operational plans for modern industrial production, which 
International Journal of Mathematical, Engineering and Management Sciences

Vol. 4, No. 6, 1434-1447, 2019

https://dx.doi.org/10.33889/IJMEMS.2019.4.6-113

has a hierarchical structure of execution and management subsystems, can be implemented in real time using specialized recognition systems (Chukin et al., 2016a, Bataev et al., 2019):

- the facts of the emergence of problematic production situations in the course of the implementation of operational schedules of production in time and space;

- Management levels that are competent in resolving the recognized PPS at the workplace, site, in the workshop, service, plant management, and establishing eligible decision-makers (DM) at these management levels to resolve this PPS;

- decisions to eliminate the effects of disturbances causing threats, negative deviations in the course of production from the planned state at the factory, interdepartmental, shop floor, district levels and the workplace;

- decisions on the use of potential opportunities, positive deviations in the course of production from the planned state at the factory, inter-shop, shop floor, district levels and the workplace;

- the facts of the need to make changes to the operational calendar production plans during the quarter, month, five-day period, day, shift at the factory, inter-shop, shop, district levels;

- decisions on the correction of operational schedules of production during the quarter, month, five-day, day, shift at the factory, inter-shop, shop, district levels.

In the operational management of innovative processes of preparation of production (scientific, design, technological, organizational) problems of recognition of problem situations (PS), solved with the use of SRS, are:

- ascertaining the occurrence of PS;

- recognition of solutions to eliminate the effects of perturbations in scientific, design, technological, organizational preparation of production (SDTOPP);

- recognition of the need to change the annual plans of SDTOPP;

- Recognizing decisions to adjust SDTOPP annual plans;

- Recognition of the need to make changes to the summary work plans by themes, plans for organizational and technical measures, SDTOPP annual work plans by quarter, quarterly by month, and within the current month by five-day breakdown;

- recognition of decisions on adjusting the summary work plans for topics, plans for organizational and technical measures, work plans for SDTOPP annual divisions, broken down by quarter, quarterly by month, and within the current month, broken down by fiveday periods.

- In the operational management of the processes of functional maintenance of production and innovation processes (for example, logistics), problem solving problems (PS) solved using SRS are:

- a statement of the fact of the PS;

- recognition of solutions to eliminate perturbation results;

- recognition of the need to amend the annual, quarterly plan to meet the needs of the enterprise in materials, components, hardware, etc. (MCPTI), in the schedule for a month, five days, a working day;

- recognition of decisions to adjust the annual, quarterly plan to meet the needs of the company in MCPTI, the schedule for the month, five days, a working day. 
International Journal of Mathematical, Engineering and Management Sciences

Vol. 4, No. 6, 1434-1447, 2019

https://dx.doi.org/10.33889/IJMEMS.2019.4.6-113

Information (initial data) about the emerged problematic production situations, fixed by specialized systems of recognition of a specific purpose, used in the processes implemented at the enterprise, differ. For example, a specialized solution recognition system for the correction of shift jobs (SJ) to the site of the machining workshop captures the data:

(i) reduction of the work time fund of the equipment of the workplace involved in SJ by an amount exceeding the permissible value;

(ii) reduction of the labor time resource of the workplace involved in SJ by an amount exceeding the permissible level;

(iii) lack of the material resource necessary to perform the planned SJ work;

(iv) insecurity of the planned SJ work with auxiliary resources (tools, equipment, software, technical documentation, etc.);

(v) the presence of guidance from the management on the removal of work with SJ;

(vi) lower workplace productivity below the acceptable level;

(vii) the provision of backup jobs to SJ with reserve resources for equipment and labor;

(viii) the provision of "stragglers" from SJ works with resources for equipment and labor;

(ix) provision of disturbing work with resources for equipment and labor, etc.

The results of the statistics of the emergence of the PS during the execution of the SJ machining section within a month, which necessitated the correction of SJ, are reflected in the histogram below (Figure 1). On the abscissa axis, the above mentioned types of problem situations are reflected, and on the ordinate axis - the number of emerging PS.

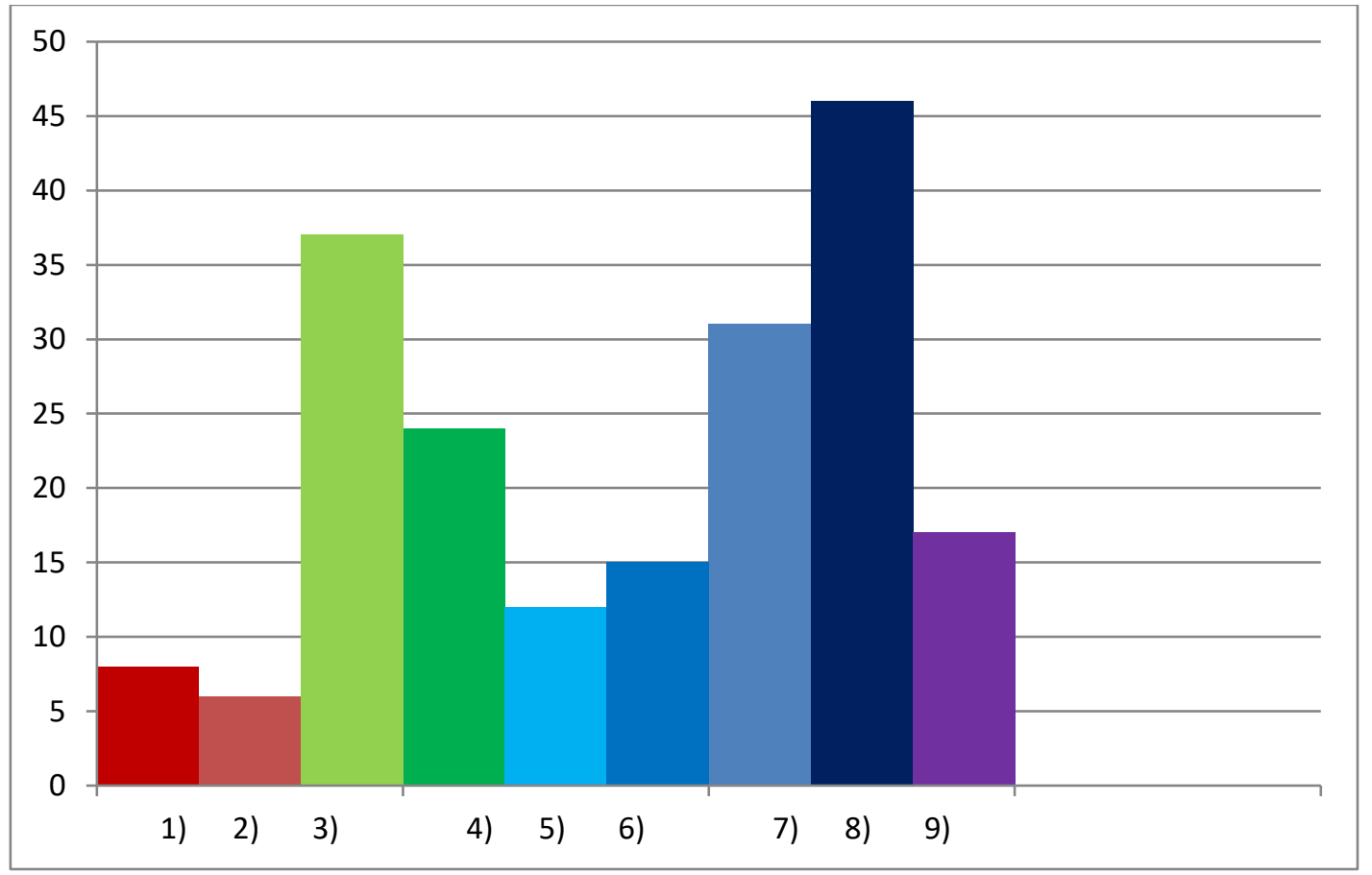

Figure 1. Example of a figure caption 
International Journal of Mathematical, Engineering and Management Sciences

Vol. 4, No. 6, 1434-1447, 2019

https://dx.doi.org/10.33889/IJMEMS.2019.4.6-113

A specialized system for recognizing the state of resources in the departments of the enterprise, required to develop solutions for the organization of replacement of failed tools, technological equipment - technological equipment (TE) in the performance of work of the shift task to the workshop site, records data on:

- faulty TE, which is the cause of the failure of the replacement job to the workshop site;

- the possibility of organizing an urgent repair of a repair workshop for a defective TE by the workshop for an acceptable time interval for the delay in performing work at the workplace;

- the presence of an identical serviceable TE in the tool-distributing pantry (TDP) of this workshop;

- presence of a similar TE in the TDP of the given workshop;

- presence of an identical good TE in the TDP of the workshop (production unit);

- the presence of an identical serviceable TE in the central instrument warehouse (CIWs) of the enterprise;

- presence of a similar TE in the TDP of the workshop;

- presence of a similar TE in the CIWs of the enterprise;

- the possibility of the urgent production of an identical or similar TE in the instrumental production of the enterprise;

- the possibility of an emergency supply of an identical or similar TE in a CIW enterprise from outside;

- the possibility of including an identical or similar TE in the supply plan from the party or in the plan for tool production of the enterprise.

To collect, transmit input information about a problem situation that has arisen in the production and economic activities and transform it into an output specialized recognition system, various technical means and systems are used. For example, sensors that record the parameters of the execution processes; software and hardware for the implementation of recognition algorithms; local area networks; means and communication systems; automated workplaces of management personnel at various levels of enterprise management, etc. (Chukin et al., 2016b). At various stages of the life cycle of a specialized recognition system, industrial and production personnel, engineering and technical, administrative and managerial in the processes of its design and creation can participate; in the system of collecting the initial information about the recognized elements of the environment; in the analysis (examination) of intermediate and final recognition results; in the learning process of the recognition system, if the recognition system is "with training"; in making decisions on the implementation of recommendations developed by the system of recognition and a number of other works.

In the design, creation and operation of specialized systems for recognizing problematic production situations, a number of tasks and the use of various methods in the course of their solution are required. These problems and methods are considered in a number of works, for example: Gorelik (1985), Verhagen (1985), Volochienko (2008). The initial task is the formation of a team (team) of specialists who implement the development, production and operation of a specialized system for recognizing a specific purpose. Then it is necessary to formulate the goals expressing the desired state of the results of its creation and functioning. Determine the set of "their" input elements for the recognition system. Establish the principle of classification of candidate elements for recognition. That is, the rule for performing the partitioning of incoming elements to the input of the recognition system into reference classes. Get reliable information 
International Journal of Mathematical, Engineering and Management Sciences

Vol. 4, No. 6, 1434-1447, 2019

https://dx.doi.org/10.33889/IJMEMS.2019.4.6-113

about the elements - candidates for recognition.

The next tasks are: development of the alphabet of the reference classes of the recognition system; the development of the composition of the characteristics characterizing the elements - candidates for recognition, i.e. dictionary of signs; execution of the description of the reference classes in the language of the signs included in the characteristics dictionary; the development of recognition algorithms that assign the candidate element to be recognized to a certain reference class; selection, creation of technical facilities and systems for obtaining input information on the values of the features of the environmental elements under study during the operation of the recognition system; the development of the optimal structure of the recognizing system and an effective control algorithm for its functioning. The solution of these problems, as a rule, is carried out iteratively (Marina et al., 2017).

The iteration is caused by the need to find an acceptable solution for the entire set of these tasks in the presence of constraints in the solution of each of them. First, the composition of the classes of the recognition system is formed according to the established classification principle - develop an a priori class alphabet. From the most complete list of characteristics characterizing the recognized elements of the environment, the possible for use in the description of classes in the language of characteristics, concerning which there is a principal possibility of technical realization of obtaining information about them in the course of the functioning of the recognition system. Such characteristics are included in the a priori vocabulary of characteristics. A preliminary description of classes in the language of signs and the development of recognition algorithms is carried out.

Then, in the conditions of limited availability of resources, the real feasibility of obtaining information on all the attributes of the a priori dictionary at the stage of the recognition system operation is estimated. If such a possibility exists, then the composition of the a priori dictionary is transformed into a working vocabulary of characteristics, and the a priori alphabet of classes is transformed into a working dictionary. Otherwise, the composition of the a priori vocabulary of features is cyclically reduced (transforming it into a working dictionary of features), taking into account the in formativeness of each characteristic and the amount of available resources for the technical realization of obtaining information about them, criteria for the effectiveness of the recognition system, algorithms of recognition. If necessary, it is also possible to narrow the alphabet of the classes of the recognition system until the desired compromise is obtained. As a result of iterations, the a priori formed alphabet of classes is transformed into the final version, called the working alphabet of the reference classes.

The following tasks serve to assess the degree of achievement of the established indicators of the quality of its functioning, to provide information about the results of recognition to the user, to maintain the recognition system in an operational state during operation.

The solution of a number of these tasks is carried out using various methods. For example, in data analysis processes, it is possible to use discriminant analysis to construct separating functions in the attribute space, to isolate and select characteristics for narrowing the excessive set of characteristics to a subset of "best features" or their combinations, cluster analysis for dividing data into similar groups of objects. To process a priori information of a logical nature, it is advisable to apply the algebra of logic, stochastic nature - the theory of probability, mathematical statistics, matrix theory, set theory, etc. In the development of the recognition system, methods of operations research, game theory, decision theory, fuzzy sets theory, etc. are also used. 
International Journal of Mathematical, Engineering and Management Sciences

Vol. 4, No. 6, 1434-1447, 2019

https://dx.doi.org/10.33889/IJMEMS.2019.4.6-113

\section{Models of Specialized Systems for Recognizing Problematic Production Situations}

The theory, methodology, methods and results of development and implementation of a number of models of specialized systems for a real-time recognition of problem situations arising in the implementation of operational plans of modern industrial production, which has a hierarchical structure of execution and management subsystems, are considered in (Volochienko, 2007; Volochienko, 2008; Rubin et al., 2016). For example, specialized systems for recognizing problem situations that require: establishing the level of management responsible for the development and adoption of management decisions in the production system; adoption of standard management decisions on the organization of replacement of failed tools in the production process; making decisions on the correction of the shift job assignment of the primary production system during the work shift.

Models of said specialized recognition systems include: the selected principle for classifying problem situations; developed alphabet of reference classes of problem situations; formed working dictionary of informative logical signs of problem situations; description of reference classes of problem situations in the language of logical characteristics - established relationships between characteristics and classes, expressed in the language of logic algebra (Boolean relations); algorithm for recognizing problem situations.

An artificial neural network (ANN) is a promising means of implementing these specialized systems for recognizing problematic production situations in production systems with intellectual support (the digital production economy). An artificial neural network can be represented in the form of a distributed parallel processor that accumulates experimental knowledge and provides them for subsequent processing. In the INS, it is possible to implement a learning procedure based on data, with or without the teacher's participation. It is possible to organize the self-study of ANN - to obtain an informed result based on data that was not found in the learning process. The control systems of the industrial, innovative processes and processes of functional maintenance of industrial and innovation processes with embedded INS can have, for example, the properties of: non-linearity, input information to output, adaptability, obvious response, fault tolerance, and a number of others that determine a qualitatively new level of their functioning.

There are three fundamental classes of ANN architectures: single-layer networks of direct distribution, multilayered networks of direct distribution, recurrent networks. In a single-layer network of direct propagation (acyclic network), the source data of various sources enter the nodes of the input layer, the information from which is transmitted only in the forward direction to the output layer of neurons (computational nodes).

In a multilayered neural network, neurons are arranged in layers. A multilayer neural network of direct propagation is characterized by the presence of one or more hidden layers, the nodes of which are called hidden neurons (hidden elements), whose function is to mediate between the external input signal and the output of the neural network. The nodes of the source of the input layer of the multilayer network of direct propagation form the input vector (input signal) arriving at neurons (computational elements) of the first hidden layer, whose output signals are used as inputs for the second hidden layer, etc. The set of output signals of the neurons of the output (last) layer of the network determines the overall response of the network to this input image formed by the nodes of the source of the input (first) layer. 
International Journal of Mathematical, Engineering and Management Sciences

Vol. 4, No. 6, 1434-1447, 2019

https://dx.doi.org/10.33889/IJMEMS.2019.4.6-113

A recurrent neural network, in contrast to a network of direct propagation, is characterized by the presence of one or multiple feedbacks. For example, a recurrent network can consist of a single layer of neurons (no hidden neurons), each of which sends its output signal to the inputs of all other layer neurons. Another structure of the recurrent network can have a hidden layer with hidden neurons and feedbacks, both from the hidden and from the output neurons. The presence of feedbacks in recurrent neural networks exerts a direct influence on the ability of such networks to learn and their performance (Babkin et al., 2018).

These ANN architectures, oriented to the analysis of large volumes of data, are called upon to realize in the digital economy of industrial enterprises (production systems) specialized systems for recognizing problematic production situations for various purposes, which are the basic core of intellectual decision support systems in RT. However, to obtain the necessary amounts of data for the effective use of artificial neural networks (mathematical models and their software implementations built on the principle of organization and functioning of biological neural networks) in complex objects, to which the production systems relate are very problematic. Production systems, as complex, large organizational and economic systems, are characterized by non-reproducibility of experiments, nonstationary characterization of processes, stochasticity and other "unpleasant" properties that significantly hamper the collection of sufficient amounts of data for realizing machine learning of artificial neural networks and their application in real time. For example, in order to recognize problem situations and make adequate decisions to regulate the implementation of strategic, tactical and operational plans for the production of products, perform work, provide services to the enterprise; real-time recognition of levels of the management hierarchy "from equipment to the ministry", authorized to solve problem situations arising at different levels of execution and management of the enterprise, region, industry.

Therefore, it seems expedient to first use artificial neural networks for the specified purposes for the implementation of specialized systems for recognizing objects, processes, problem situations (elements) in production systems developed on the basis of domestic theory and practical experience. For example, the theoretical foundations for the creation of recognition systems for various purposes are set forth in (Gorelik and Skripkin, 1974; Skripkin, 1980; Gorelik and Skripkin, 2004). They consider the methods of constructing recognition systems oriented to the implementation of detailed study, the use of analytical thinking in the study of recognizable elements, allowing the development of specialized recognition systems in conditions of limited volumes of data on the elements being studied. The methodology and examples of practical experience in the development of specialized systems for recognizing problem situations without training in modern industrial production are reflected in the works (Volochienko, 2007, 2008; Volkova et al., 2018).

As data on the problematic situations that arise in the production system are accumulated, used in the process of the functioning of specialized systems for recognition of problem situations without training implemented on ANN, a real opportunity will arise for using ANNs oriented at analyzing large volumes of data to create such recognition systems with machine learning, self-learning, which will have the properties of adaptability, flexibility, recognition accuracy exceeding recognition systems without training. Methods and systems of recognition are one of the varieties of basic tools for building production systems with intellectual support - the digital economy of an enterprise. 
International Journal of Mathematical, Engineering and Management Sciences

Vol. 4, No. 6, 1434-1447, 2019

https://dx.doi.org/10.33889/IJMEMS.2019.4.6-113

\section{The Results}

The experienced use of specialized systems for recognizing problematic production situations in the course of performing shift tasks by the machining sites of machine-building enterprises, for example, provides:

- reduction of intramuscular loss of working time by $3-9 \%$ of the working time fund of the implementation facility;

- $\quad$ an increase in the volume of production by $3-10.8 \%$;

- reduction in the number of management employees by $7-12 \%$;

- reduction of overtime pay for $10-29 \%$;

- Reduction of the duration of the production cycle for manufacturing items by $5-16 \%$.

The prospective application of specialized systems for the recognition of problem situations (SSRPIS) in the implementation of purposeful industrial and economic activities of manufacturing enterprises with intellectual support is due to a number of their advantages (Volochienko, 2017; Rudskaia, 2019). One of the important advantages of SSRPIS is the high speed of their operation, counted in fractions of a second, seconds in recording the occurrence of a problem situation, in performing its analysis and classifying such problem situations as a reference class. The price of such speed is the cost of time and financial resources in the design, creation and maintenance of software, hardware and systems implementing SSRPIS.

The high speed of the establishment of a reference class of problem situations, to which the emerging problem situation relates, allows the development of rational management solutions for resolving a problem situation to be implemented by specialized recognition systems in the RMW. This creates the conditions for the management personnel to make the proposed SSRPIS or adjusted decisions in the rhythm of production, which significantly reduces the time, labor and financial resources in comparison with the traditionally used management technologies.

Another advantage of SSRPIS, which creates non-alternative conditions for their successful application, is the lack of the need to use mathematical models of the investigated production situations, processes, which is an obligatory attribute of the application of modeling methods for decision-making. To recognize problematic production situations, it is sufficient to have only information about them that are necessary only for establishing the values of the informative features included in the dictionary of features of the recognizing system at the stage of its design.

Another advantage of using SSRPIS is the possibility of switching from the traditional method of production management "by deviation and partly by indignation" to an innovative way of managing production "by indignation and partly by deviation". That positively influences the efficiency of the operation and development of the enterprise by realizing the possibility of preventing the occurrence of unacceptable deviations in the production and economic activities of enterprises when making decisions in the RT that localize the effect of controlled perturbations of the external and internal environment of the enterprise and aimed at neutralizing the emerging threats or realizing potential opportunities.

Another advantage of using SSRPIS in production management is the creation of prerequisites for the transition from information systems of production management to information-advising, and then to control systems based on the use of artificial neural networks, artificial intelligence. 
International Journal of Mathematical, Engineering and Management Sciences

Vol. 4, No. 6, 1434-1447, 2019

https://dx.doi.org/10.33889/IJMEMS.2019.4.6-113

The main disadvantage of using SSRPIS in the subsystems of execution and management of an enterprise, or rather the main requirement, is the availability of a sufficient level of automation of execution and control processes based on the use of modern technical means and systems, information technologies and organizational solutions. This is necessary to realize the possibility of information interaction in RT embedded in the execution and management of specialized systems for recognizing objects, situations, processes, etc.

\section{Conclusion}

The use of specialized systems for recognizing the problematic situations in the composition of automated (automatic) production and economic management systems of an enterprise (production system) with intellectual support will allow:

- innovative way of production management "by perturbation and partially by deviation" due to the possibility of exercising in RT control a wide range of perturbations of the external and internal environment of the enterprise at the time of their occurrence and fixing inadmissible deviations of the actual state of objects from those required in the execution and control subsystems;

- address setting in RT of the competent level of production management and DM (individual or group) in resolving the problematic production situation that has arisen, instead of the traditionally used technology of sequential analysis of the possibility of its resolution by hierarchy levels in execution and management subsystems;

- formalization of functions of operational management of production, innovation processes and processes of functional maintenance of production and innovation processes in RT at all levels of the hierarchy of the production and organizational structure of the enterprise due to high speed;

- organizational innovations in risk management and controlling of production systems (Volochienko, 2006; Badalova and Volochienko, 2014);

- translation of information systems of production management into informational and advisory, and then into control systems due to intellectualization based on the use of modern information technologies, technical means and systems for collecting, transmitting and processing information, artificial neural networks, artificial intelligence, etc. solutions.

The implementation of these aspects of improving production management will significantly increase the efficiency of the functioning and development of industrial enterprises with intellectual support.

\section{Conflict of Interest}

The authors confirm that there is no conflict of interest to declare for this publication.

\section{Acknowledgement}

The research carried out with the support of Moscow State Technical University named N.E. Bauman. 
International Journal of Mathematical, Engineering and Management Sciences

Vol. 4, No. 6, 1434-1447, 2019

https://dx.doi.org/10.33889/IJMEMS.2019.4.6-113

\section{References}

Babkin, A.V., Burkaltseva, D.D., Betskov, A.V., Kilyaskhanov, H.S., Tyulin, A.S., \& Kurianova, I.V. (2018). Automation digitalization blockchain: trends and implementation problems. International Journal of Engineering and Technology, 7(3.14 Special Issue 14), 254-260.

Badalova, A.G., \& Volochienko, V.A. (2014). The main aspects of application of methods of pattern recognition in risk management of production systems. Vestnik of MSTU "STANKIN", 4(31), 220-224.

Bataev, A.V., Gorovoy, A.A., \& Mottaeva, A. (2019). Evaluation of the future development of the digital economy in Russia. In 32nd International Business Information Management Association Conference, IBIMA2018 - Vision 2020: Sustainable Economic Development and Application of Innovation Management from Regional Expansion to Global Growth, 88-101. Seville, Spain.

Blagoveshchenskaya, E.A., Dashkina, A.I., Lazovskaya, T.V., Ryabukhina, V.V., \& Tarkhov, D.A. (2016, July). Neural network methods for construction of sociodynamic models hierarchy. In International Symposium on Neural Networks, (Vol. 9719, 513-520). Springer, Cham.

Bosikova, E., Polyakova, M., \& Rubin, G. (2017). A new approach to the assessment of the analysis method accuracy. In Key Engineering Materials, (Vol. 743, pp. 454-458). Trans Tech Publications.

Chernykh, G.A., Kuperin, Y.A., Dmitrieva, L.A., \& Navleva, A.A. (2016, July). Calculation of analogs for the largest lyapunov exponents for acoustic data by means of artificial neural networks. In International Symposium on Neural Networks, (Vol. 9719, 108-114). Springer, Cham.

Chukin, M.V., Emaleeva, D.G., Polyakova, M.A., \& Gulin, A.E. (2016a). Status and prospects of deformational methods for refining the microstructure of bulk materials. Metallurgist, 60(3-4), 299305. Springer.

Chukin, M.V., Polyakova, M.A., \& Gulin, A.E. (2016b). Influence of hybrid plastic deformation on the microstructure and mechanical properties of carbon-steel wire. Steel in Translation, 46(8), 548-551.

Drobintsev, P.D., Kotlyarov, V.P., \& Letichevsky, A.A. (2014). A formal approach to test scenarios generation based on guides. Automatic Control and Computer Sciences, 48(7), 415-423.

Gazizulina, A., Eskina, E., Vasilieva, I., \& Valeeva, O. (2017). The reasons for the increase in selforganization in companies. International Journal of Reliability, Quality and Safety Engineering, 24(06), 1740002.

Gorelik, A.L. (1980). General statement of the problem of recognition of objects and phenomena. Cybernetics, 6, 72-75.

Gorelik, A.L. (1985). Modern status of the problem of recognition (Vol. 6). Moscow: Radio and Communication.

Gorelik, A.L., \& Skripkin, V.A. (1974). Some problems of building recognition systems. M., Sov. Radio, pp. 224.

Gorelik, A.L., \& Skripkin, V.A. (2004). Methods of recognition: proc. the manual for high schools. Spanish. M.: Higher School, 4(1), 261.

Grishunin, S., \& Suloeva, S. (2017). Development of the credit risk assessment mechanism of investment projects in telecommunications. In Internet of Things, Smart Spaces, and Next Generation Networks and Systems, (10531, pp. 300-314). Springer, Cham.

Gromova, E.A. (2019). Digital economy development with an emphasis on automotive industry in Russia. (Desarrollo de la economía Digital con énfasis en la industria automotriz en Rusia) Espacios, 40(6), 27

Heikin, S. (2006). Neural networks: full course, 2nd edition. TRANS. from English. M.: Publishing house "Vil'yams", (2), 865-881 
International Journal of Mathematical, Engineering and Management Sciences

Vol. 4, No. 6, 1434-1447, 2019

https://dx.doi.org/10.33889/IJMEMS.2019.4.6-113

Izmaylov, R., \& Lebedev, A. (2015). Centrifugal compressor surge detecting method based on wavelet analysis of unsteady pressure fluctuations in typical stages. In IOP Conference Series: Materials Science and Engineering, 90(1), 012052. IOP Publishing.

Klochkov, Y., Gazizulina, A., Golovin, N., Glushkova, A., \& Zh, S. (2017a, December). Information model-based forecasting of technological process state. In 2017 International Conference on Infocom Technologies and Unmanned Systems (Trends and Future Directions)(ICTUS), (pp. 709-712). IEEE. Dubai, United Arab Emirates.

Klochkov, Y., Klochkova, E., Didenko, N., Frolova, E., \& Vlasova, N. (2017b, December). Development of methodology for assessing risk of loss of a consumer through the fault of an outsourcer. In 2017 International Conference on Infocom Technologies and Unmanned Systems (Trends and Future Directions) (ICTUS), (pp. 719-724). IEEE. Dubai, United Arab Emirates.

Kostin, G.A., Pokrovskaia, N.N., \& Ababkova, M.U. (2017, October). Master-chain as an intellectual governing system for producing and transfer of knowledge. In 2017 IEEE II International Conference on Control in Technical Systems (CTS), (pp. 71-74). IEEE, St. Petersburg, Russia.

Polyakova, M., Golubchik, E., Efimova, Y., \& Gulin, A. (2017). Modern engineering techniques for designing materials with a specified set of properties. In Key Engineering Materials, (Vol. 724, pp. 7783). Trans Tech Publications.

Rubin, G.Sh., Chukin, M.V., Gun, G.S., \& Polyakova, M.A. (2016). Analysis of the properties and functions of metal components. Steel in Translation, 46(10), 701-704.

Rudskaia, I. (2019). Transformation of manpower resources within the "digital economy" program. In 32nd International Business Information Management Association Conference, IBIMA 2018 - Vision 2020: Sustainable Economic Development and Application of Innovation Management from Regional Expansion to Global Growth, pp. 3627-3631.

Rudskoy, A.I., Borovkov, A.I., Romanov, P.I., \& Kolosova, O.V. (2019). Ways to reduce risks when building the digital economy in Russia. Educational Aspect. Vysshee Obrazovanie v Rossii, 28(2), 922.

Silkina, G.Y. (2017). Information and communication technologies in ensuring of innovative development. Paper presented at the Proceedings of the 29th International Business Information Management Association Conference - Education Excellence and Innovation Management through Vision 2020: From Regional Development Sustainability to Global Economic Growth, pp. 1165-1176.

Verhagen, K., Verhagen, R., \& Dayan, F. (1985). Grun and others, "pattern recognition: status and prospects". Radio and Communication, pp. 160.

Volkova, V.N., Kozlov, V.N., Karlik, A.E., \& Iakovleva, E.A. (2017, November). The impact of NBICtechnology development on engineering and management personnel training. In 2017 IEEE VI Forum Strategic Partnership of Universities and Enterprises of Hi-Tech Branches (Science. Education. Innovations)(SPUE), (pp. 51-54). IEEE. St. Petersburg, Russia.

Volochienko, V.A. (2006). Controlling the implementation of the operational tasks of machine-building production. Journal of the Association of Controllers "Controlling", 20, 68-76.

Volochienko, V.A. (2008). Management of modern industrial production on the basis of recognition of problem situations. Central Economics and mathematics Institute Russian Academy of Sciences. Moscow, Russia.

Volochienko, V.A. (2007). The organization of management of production process of the machine-building enterprise on the basis of recognition of problem situations (Theory, methodology, methods of realization) (Vol. 1). The Monograph. - M.: GOU VPO at MSFU, pp. 216. 
International Journal of Mathematical, Engineering and Management Sciences

Vol. 4, No. 6, 1434-1447, 2019

https://dx.doi.org/10.33889/IJMEMS.2019.4.6-113

Volochienko, V.A. (2017). Recognition of problem situations-organizational innovation in production management. Organizer of Production, 25(1), 59-68.

Volochienko, V.A., \& Falco, S.G. (2016). Situational production management. Bulletin of the South 600 Russian State Technical University (NPI), 1, 4-14.

Zegzhda, P.D., Malyshev, E.V., \& Pavlenko, E.Yu. (2017). The use of an artificial neural network to detect automatically managed accounts in social networks. Automatic Control and Computer Sciences, 51(8), 874-880. 